\title{
EFEKTIVITAS BANTUAN PENINGKATAN INDEKS PERTANAMAN MELALUI KLASTER TERHADAP PENINGKATAN PENDAPATAN USAHATANI PADI DI KECAMATAN TAMBAN CATUR KABUPATEN KAPUAS
}

\author{
${ }^{1}$ Origen J.F. Saragih, ${ }^{2}$ Yuni Erlina, ${ }^{3}$ Trisna Anggreini \\ ${ }^{1}$ Alumnus Program Studi Agribisnis Fakultas Pertanian Universitas Palangka Raya \\ ${ }^{2,3}$ Dosen Program Studi Agribisnis Fakultas Pertanian Universitas Palangka Raya \\ E-mail: saragih106@gmail.com
}

\begin{abstract}
This study aims to determine the description of cluster rice farming in Warna Sari Village; analyzing the effectiveness of assistance to increase the cropping index through clusters to increase rice farming income in Warna Sari Village, Tamban Catur, Kapuas Regency. The research was conducted in the Warna Sari village subdistrict Tamban Catur Kapuas District, sampling methods intentionally that farmers who are members and actively participate in the program. To answer the research objectives, direct interviews were conducted with farmers who were equipped with a questionnaire that had been provided. The analysis used is the analysis of farm income; descriptive statistical analysis; paired sample $t$-test. The results of this study indicate that after the cluster program farmers can carry out two planting seasons in one year. The types of seeds used were Karang Dukuh local siam rice and Inpara 3 superior rice. The use of production facilities after the cluster was more efficient than before the cluster. The average income before the cluster was IDR. 16,060,893 and after the cluster was IDR. 35,833,943 with a difference of IDR. 19,773,050. Sig value. obtained is $0.02<0.05$, which states that the cluster is effective in increasing rice farming income in Warna Sari Village.

Keywords: Income, Farming, Paddy Cluster, Effectiveness, Plantation Index.
\end{abstract}

\section{PENDAHULUAN}

Indonesia yang beriklim tropis merupakan negara dengan keanekaragaman hayati terbesar kedua di dunia setelah Brazil. Indonesia memiliki sekitar 25.00030.000 spesies tanaman yang merupakan $80 \%$ dari jenis tanaman di dunia dan $90 \%$ dari jenis tanaman di Asia. Tumbuhan biofarmaka di Indonesia merupakan salah satu kelompok komoditas hutan dan kebun yang erosi genetiknya tergolong pesat. Hal ini disebabkan oleh beberapa faktor, yaitu (1) adanya kerusakan habitat disebabkan oleh desakan kebutuhan lahan untuk produksi maupun tempat tinggal, sehingga membuat habitat tumbuhan biofarmaka dapat terganggu, (2) adanya kurang perhatian terhadap budi daya tanaman biofarmaka, dan (3) adanya kemampuan regenerasi tumbuhan biofarmaka yang masih lambat, terutama di setiap jenis tumbuhan tahunan, terlebih lagi yang di peroleh dari alam (Djauhariya \& Sukarman, 2002).

Tanaman Biofarmaka adalah tanaman yang bermanfaat untuk obatobatan yang dikonsumsi dari bagian tanaman yang berupa daun, bunga, buah, umbi (rimpang) ataupun akar. Tanaman Biofarmaka memiliki peran penting memenuhi kebutuhan hidup 
manusia. Tanaman Biofarmaka cenderung mengalami peningkatan dengan adanya isu back to nature dan krisis ekonomi, yang mengakibatkan turunnya daya beli masyarakat terhadap obat-obat asli Indonesia sehingga masyarakat kebanyakan beralih lebih memilih obat modern seperti membeli obat kimia dimana yang saat ini obat modern relatif lebih mahal harganya dan memiliki banyak efek samping dari obat tersebut kebanyakan sudah diketahui dan tercantum dalam label atau brosur setiap obat dan menjadi perhatian baik dokter maupun apoteker (Dewoto, 2007).

Arah pengembangan tanaman biofarmaka ditujukan untuk kosmetika, industri rumah tangga, jamu gendong, dan ekspor dengan memperhatikan peluang pasar, potensi areal pengembangan, teknologi yang tersedia, kondisi saat ini dan permasalahan yang ada. Produk yang dapat dihasilkan dari tanaman temulawak, kunyit, kencur dan jahe adalah produk setengah jadi minyak, produk industri (makanan/minuman, kosmetika, farmasi, Industri Kecil Biofarmaka Tradisional (IKOT) dan Industri Biofarmaka Tradisional (IOT), dan produk jadi (sirup, instan, bedak, tablet dan kapsul) (Suryana, 2005).

Kalimantan Tengah merupakan daerah yang memiliki prospek yang sangat baik untuk pengembangan berbagai macam usaha agribisnis. Berbagai macam kegiatan agribisnis yang dapat dilakukan yaitu pertanian, perikanan dan peternakan. Penduduk asli Kalimantan sudah sejak zaman dahulu memanfaatkan tumbuhan dalam pengobatan berbagai penyakit dan dalam kehidupan sehari-hari. Etnis Dayak, Banjar, Kutai merupakan etnis asli yang ada di Kalimantan. Pengobatan tradisional yang ada pada etnis asli Kalimantan sangat beragam. Pengobatan dilakukan oleh orang yang dianggap memiliki "kepandaian" baik dalam pengetahuan penggunaan tumbuhan dan binatang hingga hal yang bersifat magis dan menggunakan mantra dalam cara pengobatannya. Pengembangan tanaman obat dan pengolahan herbal merupakan Program Dinas Kesehatan Provinsi Kalteng yang melibatkan Institusi lintas Sektoral. Untuk meningkatkan pengetahuan dan keterampilan pasca panen dan Pengolahan Obat tradisional herbal, Dinas Kesehatan Provinsi Kalteng melaksanakan Studi Banding ke Pusat Saintifikasi dan Pelayanan Jamu (PSPJ) Kab. Pekalongan Jawa Tengah untuk mendalami preparasi dan pengolahan jamu/herbal dengan sistem mekanisasi bersama Tim Lintas Sektoral (Noorcahyati, 2014).

Kota Palangka Raya memiliki berbagai komoditas pertanian, termasuk didalamnya komoditas tanaman Biofarmaka. Hasil pertanian di wilayah kota Palangka Raya mulai dikembangkan oleh pemerintah. Pengembangan tanaman biofarmaka di kota Palangka Raya dilakukan untuk melestarikan dan membudidayakan tanaman biofarmaka, selain itu di kota Palangka Raya juga dilakukan pengembangan hasil pengolahan tanaman biofarmaka sebagai wadah mengembangkan Industri pengolahan tanaman Biofarmaka di kota Palangka Raya. Dalam lingkup perdagangan, pengolahan hasil pertanian menjadi produk olahan ditujukan untuk meningkatkan nilai tambah komoditas. 
Salah satu industri pengolahan tanaman biofarmaka yang ada di kota Palangka Raya adalah C.V. M4 Bersaudara menggunakan bahan asli dari tanaman dan tidak memiliki bahan campuran yang didirikan pada Tahun 2000, dimana C.V. M4 Bersaudara pernah hampir mengalami kegagalan di karena kurangnya dukungan dari pemerintah. Pemilik C.V. M4 Bersaudara ini telah mengikuti pelatihan dari dinas yang terkait. Tenaga kerja yang ada di C.V. M4 Bersaudara ini kebanyakan dari luar daerah, karena kurangnya minat masyarakat dan pengendalian produksi masih dilakukan oleh pemilik itu sendiri.

Tujuan penelitian ini adalah mengetahui gambaran umum industri pengolahan tanaman Biofarmaka C.V. M4 Bersaudara di Kota Palangka Raya.

\section{METODE PENELITIAN}

Penelitian ini dilaksanakan di Jalan. Bangaris, Kelurahan Tanjung Pinang, Kota Palangka Raya, Provinsi Kalimantan Tengah. Pemilihan lokasi dilakukan secara sengaja (purposive sampling) dengan pertimbangan bahwa C.V. M4 Bersaudara merupakan usaha produk tanaman biofarmaka yang terdaftar di Dinas Perindustrian dan Perdagangan Kota Palangka Raya, dan merupakan salah satu industri pengolahan produk tanaman biofarmaka yang memiliki beberapa produk unggulan yang banyak diminati oleh masyarakat Kota Palangka Raya.

Metode yang digunakan dalam penentuan sampel adalah metode purposive sampling. Menurut Sugiyono (2010) metode purposive sampling pada dasarnya dilakukan sebagai sebuah metode yang secara sengaja mengambil sampel tertentu yang telah sesuai dan memenuhi segala persyaratan yang dibutuhkan yang meliputi : sifat-sifat, karakteristik, ciri dan kriteria sampel tertentu.

Data yang dikumpulkan dalam penelitian ini meliputi data primer dan data sekunder. Data primer diperoleh dari hasil wawancara secara langsung dengan pengusaha industri secara langsung dengan menggunakan kuesioner. Kuesioner disini digunakan untuk mendapatkan informasi dari narasumber. Informasi yang akan digali meliputi, aspek produksi, pemasaran serta kendalakendala yang dihadapi dalam industri pengolahan tanaman biofarmaka di C.V. M4 Bersaudara. Sedangkan data sekunder yang di peroleh dari instansi terkait yang sesuai dengan tujuan penelitian. Teknik pengumpulan data yang utama adalah dengan wawancara mendalam yang dibantu dengan pedoman wawancara, serta observasi secara langsung (Burhan, 2007).

Metode yang digunakan dalam pengumpulan data yaitu metode observasi dan metode studi kepustakaan. Metode observasi yaitu metode yang dilakukan melihat dan mengamati langsung objek penelitian. Metode studi kepustakaan yaitu metode pengumpulan data yang dilakukan dengan cara mengutip atau mengambil data yang berasal dari sumber yang sudah diolah dari pihak lain.

Pemilihan informan kunci sebagai sumber data dalam penelitian ini adalah berdasarkan subjek yang menguasai permasalahan, memiliki data dan bersedia memberikan data lengkap dan akurat. Dalam hal ini informan kunci yang dimaksud adalah pemilik industri produk tanaman biofarmaka C.V. M4 
Bersaudara Informan diambil berdasarkan dengan penggunaan metode sampel yaitu pemilik, pihak pemerintah selaku pemegang kebijakan Dinas Perindustrian dan Perdagangan Kota Palangka Raya. Informan kunci, yaitu orang yang mengetahui informasi pokok yang diperlukan dalam penelitian (Suyanto, 2005).

Studi kasus merupakan penelitian tentang status subjek penelitian yang berkenan dengan suatu fase spesifik atau khas dari keseluruhan personalitas. Tujuan studi kasus adalah untuk mempelajari secara intensif tentang latar belakang keadaan sekarang dan interaksi lingkungan, individu, kelompok, lembaga, dan masyarakat (Suryabrata, 2003).

Data analisis yang dilakukan di C.V. M4 Bersaudara akan didapat melalui proses wawancara, pengamatan, dan penilaian di lapangan, dimana hasilnya akan diolah dengan cara analisis menggunakan metode deskriptif kualitatif.

Agar dapat menjawab tujuan pertama maka dapat digunakan analisis deskriptif kualitatif. Dimana peneliti mencari informasi dengan terperinci dan menyeluruh hal-hal yang berkaitan dengan keadaan umum industri pengolahan tanaman Biofarmaka C.V. M4 Bersaudara. Pada dasarnya penelitian deskriptif kualitatif merupakan suatu metode dalam meneliti status kelompok manusia, suatu objek, suatu set kondisi, suatu sistem pemikiran ataupun suatu kelas peristiwa pada manusia sekarang (Sugiyono, 2007).

\section{HASIL DAN PEMBAHASAN}

\section{Gambaran Umum Industri Pengolahan Tanaman Biofarmaka C.V. M4 Bersaudara}

Hasil olahan tanaman biofarmaka yang diproduksi oleh C.V. M4 Bersaudara terdiri dari beberapa bentuk variasi yaitu serbuk, batang, akar. Pemilik usaha memiliki kebun tanaman biofarmaka yang berjarak jauh dari tempat tinggal pemilik usaha. Berikut tahapan proses produksi tanaman biofarmaka pada C.V. M4 Bersaudara :

1. Pemilihan dan Pengambilan Tanaman Biofarmaka

Pembuatan produk biofarmaka, tanaman biofarmaka merupakan salah satu bahan baku yang utama. Bahan baku tanaman biofarmaka yang digunakan untuk membuat produk di C.V. M4 Bersaudara adalah tanaman biofarmaka yang asli. Pemilik C.V. M4 Bersaudara mengambil tanaman biofarmaka dari daerah Gunung Mas. Hutan Gunung Mas merupakan salah satu tempat yang masih memiliki banyak tanaman biofarmaka asli Kalimantan Tengah. Tidak semua jenis tanaman biofarmaka yang ada di Hutan Gunung Mas yang dapat di produksi menjadi produk biofarmaka dan tidak semua tanaman biofarmaka dapat diambil dengan mudah untuk dijadikan produk biofarmaka, setiap jenis tanaman biofarmaka memiliki cara khusus dalam setiap pengambilan tanaman untuk dijadikan produk biofarmaka.

2. Pengupasan

Tanaman biofarmaka yang ingin diolah menjadi produk biofarmaka sebelumnya harus terlebih dahulu dikupas. C.V. M4 Bersaudara melakukan tahap pengupasan terhadap semua jenis tanaman biofarmaka yang ingin diolah menjadi produk. Pengupasan dilakukan 
bertujuan untuk membuang kulit tanaman biofarmaka dimana kulit tersebut akan diolah lagi menjadi pupuk.

3. Pemotongan

Tanaman biofarmaka yang kulitnya sudah dikupas kemudian akan melalui tahapan pemotongan, Tahap pemotongan dilakukan bertujuan untuk membagi tanaman biofarmaka menjadi beberapa bagian. Setiap 1 jenis tanaman dipotong bisa menjadi 4 - 7 bagian. Tahap pemotongan juga dilakukan untuk menghasilkan serbuk-serbuk yang akan digunakan untuk menjadi produk biofarmaka yaitu menjadi bubuk teh.

4. Penjemuran

Selanjutnya melakukan tahap penjemuran terhadap tanaman biofarmaka yang sudah dipotong menjadi beberapa bagian. Tahap ini digunakan untuk mengeringkan tanaman biofarmaka. Tanaman biofarmaka yang sudah kering merupakan tanaman biofarmaka yang sudah aman untuk dikonsumsi. Tahap penjemuran juga dilakukan agar aroma jenis tanaman tidak hilang.

5. Mencetak Logo Kemasan

Sebelum melakukan pengemasan C.V. M4 Bersaudara mencetak logo kemasan produk biofarmaka. Kemasan tersebut digunakan agar para pembeli dapat mengetahui nama produk, manfaat dari tanaman biofarmaka, cara pemakaian, nama tanaman biofarmaka sebelum diolah, kontak person pemilik C.V. M4 Bersaudara, serta nama C.V. M4 Bersaudara tersebut.

\section{Pengemasan}

Setelah melakukan pencetakan logo kemasan C.V. M4 Bersaudara melakukan tahap pengemasan, setiap tempat pengemasan berbeda-beda sesuai dengan bentuk produk tanaman biofarmaka yang sudah di olah tersebut. Pengemasan dilakukan menggunakan sarung tangan agar tanaman biofarmaka yang dikemas masih steril tidak kotor dan bau.

\section{KESIMPULAN DAN SARAN Kesimpulan}

Berdasarkan hasil penelitian dapat disimpulkan bahwa gambaran umum industri pengolahan tanaman Biofarmaka pada industri di C.V. M4 Bersaudara adalah menggunakan bahan baku tanaman Biofarmaka alami. Dalam kegiatan pengolahan, produk tanaman biofarmaka menghasilkan 30-500 bks/bulan. Proses pengolahan tanaman Biofarmaka meliputi beberapa tahapan diantaranya: (a) pemilihan dan pengambilan tanaman biofarmaka; (b) pengupasan; (c) pemotongan; (d) penjemuran; (e) mencetak logo kemasan; (f) pengemasan.

\section{Saran}

Berdasarkan kesimpulan diatas, maka disarankan: agar pemerintah hendaknya agar lebih memperhatikan usaha C.V. M4 Bersaudara dan terus memberikan pendampingan penyuluhan kepada pengusaha industri, agar C.V. M4 Bersaudara dapat mengembangkan usaha kedepannya lagi.

\section{DAFTAR PUSTAKA}

Badan Pusat Statistik Provinsi Kalimantan Tengah. 2019. Statistik Indonesia 2019. Badan Pusat Statistik Provinsi Kalimantan Tengah. Palangka Raya. 
Burhan, Bungin. 2007. Penelitian

Kualitatif Komunikasi,

Ekonomi, Kebijakan Publik

dan Ilmu Sosial. Jakarta.

Dewoto. 2007. Pengembangan

Biofarmaka Tradisional

Indonesia Menjadi

Fitorfarmaka. Departemen

Farmakalogi. Jakarta.

Djauhariya, E. dan Sukarman. 2002.

Pemanfaatan Plasma Nutfah

Dalam Industri Jamu Dan

Komestika Alami. Buletin

Plasma Nutfah. Palangka

Raya.

Noorcahyati, S. Hut. 2014.

Tumbuhan Berkhasiat Obat

Etnis Asli Kalimantan. Balai

Penelitian Konservasi Sumber

Daya Alam. Kalimantan

Selatan. Loksado.

Sugiyono. 2007 . Metode Penelitian

Pendidikan Pendekatan Kuantitatif,

Kualitatif

Dan R\&D. Alfabeta. Bandung.

Sumadi, Suryabrata. 2003. Metode

Penelitian. PT. Raja Grafindo

Persada. Jakarta.

Suryana, Achmad. 2005. Prospek Dan

Arah

Pengembangan

Agribisnis

Tanaman

Biofarmaka. Departemen

Pertanian. Jakarta.

Suyanto, Bagong. 2005. Metode Penelitian Sosial. Kencana Prenada Media Group. Jakarta.

. 2007. Prospek

Dan Arah

Pengembangan

Agribisnis

Tanaman

Biofarmaka Edisi

Kedua. Departemen

Pertanian. Jakarta. 